\title{
Monetary Policy Behaviour over the Long Run in a Small Open Economy: A Markov-Switching Vector Error-Correction Approach
}

\author{
Ronald Henry Lange ${ }^{1, *}$ \\ ${ }^{1}$ Economics Department, Laurentian University, Sudbury, Ontario P3E 2C6, Canada \\ *Correspondence: Economics Department, Laurentian University, Sudbury, Ontario P3E \\ 2C6, Canada. Tel: 1-705-673-8051 E-mail: rlange@laurentian.ca
}

Received: May 30, 2018 Accepted: June 15, 2018 Published: August 25, 2018

doi: 10.5296/rae.v10i2.13223 URL: https://doi.org/10.5296/rae.v10i2.13223

\begin{abstract}
This study identifies a long-run equilibrium relationship among important information variables with stochastic trends for monetary policy in Canada. The variables serve as both target policy variables for the domestic macroeconomy and reaction variables to external economic disturbances. The parameters of the cointegrated vector of information variables are found to be quite stable. A Markov-switching cointegrated VAR model captures two stochastic policy regimes with low- and high-variances. The weighting matrix for the error-correction terms for both inflation and output are found to be relatively stable across regimes, while the monetary policy rate is found to exhibit asymmetric behavior with error-correction adjustment only in the current low-variance regime.
\end{abstract}

Keywords: Monetary policy, Vector error-correction autoregession, Markov-regime switching

JEL Classification: C32, E41, E52 


\section{Introduction}

In general, the empirical application of structural change to monetary policy is related to the large literature on the use of structural vector autoregressions (SVAR) to estimate the monetary transmission mechanism (see Christiano and Eichenbaum and Evans (1999) for a survey). In this research, the economy is typically modeled as innovations in a vector autoregression in which monetary policy is identified by structural restrictions on the contemporaneous impacts of the variables (Sims, 1992), on the long-run effects of shocks (Blanchard and Quah, 1989), or on both the contemporaneous and long-run effects (Gali ,1992). Some other important contributions to this literature are Bernanke and Mihov (1998), Christiano, Eichenbaum and Evans (2005), and Smets and Wouters (2002). The "structural VAR" approach has been criticized because of its limitations to identify the systematic part of monetary policy, leaving just a reaction function in surprises (Clarida, Gali, and Gertler, 2000).

However, changes in monetary policy can occur in both the implementation of policy (innovations or shocks) and the objectives of policy (regimes). Consequently, another branch of the literature has developed to address these combined issues by examining both the policy shocks and regime changes using Markov-switching vector autoregression (MS-VAR) models, such as Bernanke and Mihov (1998), Sims and Zha (2006), and Boivin and Gianonni (2002). More recent studies also include Rubio-Ramírez, Waggoner, and Zha (2005) who use various MS-SVAR models to find evidence for the European Monetary Union (EMU) that monetary policy and the volatility of euro area macroeconomic variables have changed since the introduction of the EMU in 1993. Paolillo and Petragallo (2004) use the MS-VAR methodology to find strong evidence in favour of asymmetries in the transmission mechanism of the business cycle due to the U.S. interest rate differential with Euro area and the Euro dollar exchange rate. Hubrich and Tetlow (2015) use a MS-VAR for the U.S. that includes a financial stress index to show that both variance and coefficient switching are needed to capture the linkage between financial stress and the macroeconomy.

The policy regimes in these Markov-switching studies generally involve switches in some version of the policy rule that reflects changes in policy reactions to deviations from target values or to external and financial conditions. These studies are aimed at finding persistent changes in policy that result, for example, from changes in central bank leadership or transparency due to changes in the policy framework, such as the adoption of explicit inflation targets or a monetary integration. This research shows that the stance of monetary policy is important for capturing the systematic policy reactions to economic shocks, often interpreted as the policy reaction function or the Taylor rule, which are not captured by the linear SVAR approach. In addition, these studies can also capture the contemporaneous effects of the monetary policy shock itself on target variables such as output and inflation in the regimes.

In general, the regime changes in these studies can have large effects on the volatility of money, interest rates, and output. Clarida Gali, and Gertler, (2000), for example, show that a switch in the objectives of monetary policy post-1982 has resulted in a more stable, 
inflation-controlling policy. Similarly, Boivin and Giannoni (2002) have observed that the impact of monetary policy shocks in recent studies using vector autoregressions - defined as unexpected exogenous changes in the monetary policy rate - has had a much smaller impact on output and inflation since the beginning of the 1980's.

The approach in this study differs somewhat from this previous research in that it uses a long-run identification strategy that specifies a cointegrated vector of both the target policy variables for the domestic macroeconomy and reaction variables to external economic disturbances. The cointegrated VAR approach avoids the criticism of Sims (1980) and others that recommend against differencing variables or using gaps for target variables even if the variables are not stationary since the main purpose of using the VAR methodology is not to determine the parameter estimates but to capture the inter-relationships among the variables. In this case, differencing of variables or target gaps would throw away important information concerning the comovements in the data.

A multivariate Markov regime-switching error-correction model (MS-VECM) is used in this study to determine whether the time series of the variables are subject to structural changes and whether the long-run relationships are temporally stable. The Markov switching (MS) approach originally proposed by Hamilton (1990) and later extended to multivariate time-series models by Krolzig (1997, 2001), can address structural breaks. Hamilton introduced univariate Markov switching autoregressive (MS-AR) models to study US business cycles, while Krolzig developed multivariate extensions to Markov switching vector autoregressive models (MS-VAR) and vector-error correction models (MS-VECM). The MS models fall within the category of nonlinear time-series models that emerge from nonlinear dynamic processes, such as high-moment structures, time-varying parameters, asymmetric cycles, and breaks in a time series that result from changes in regimes as random events governed by an exogenous Markov process. A latent Markov process determines the state of the economy, where the probability of the latent state process takes a certain value based on the sample information.

The identification strategy in this study is achieved through the long-run impact matrix of the vector error-correction model, where regime switches in the long run relationships are incorporated by allowing both weighting matrix of the error-correction term and the covariance matrix to switch regimes. Although the long-run relationships between the cointegrated variables are found to be the same across states, stochastic parameter variation is achieved by allowing the error-correction terms to be state-dependent. Modeling the weighting matrix as state-dependent allows variables in the model to respond differently to changes in the monetary policy vector of information variables in the long run.

Francis and Owyang (2005) use Markov-switching cointegration for domestic target variables in the U.S. economy. Clarida, Sarno, Taylor, and Valente (2006) also use a nonlinear multivariate vector equibrium-correction model to capture asymmetric adjustment and regime shifts in the term structure of interest rates. Paap and van Dijk (2003) use a multivariate Markov trend model that accounts for different growth rates in consumption and income during expansions and recessions and across variables within both regimes. They find the 
existence of a cointegration relation between U.S. per capita disposable income and consumption after correction for a multivariate Markov trend. Similarly, Hall, Psaradakis, and Sola (1997) find evidence for consumption and disposable income in Japan that favors a Markov-switching long-run relationship over a temporally stable relationship. Krolzig, Marcellino and Mizon (2002) use a MS-VECM approach to study output, employment, labour supply and real earnings in the United Kingdom.

The main contribution of this study is the identification of the existence of a long-run equilibrium relationship among important information variables that have stochastic trends for monetary policy in Canada. In general, the empirical analysis with a Markov-switching methodology found no signifcant evidence in favour of time-varying cointegration where the long-run parameters are allowed to switch stochastically between two different cointegrating regimes. A single cointegrating vector of reaction variables for both the domestic macroeconomy and external disturbances is found to be quite stable, indicating that the parameters are time independent and not subject to structural changes. The MS-VECM captures two stochastic policy regimes with low- and high-variances for some of the variables in the policy vector. Despite the regime-switches in the variances of the variables, the long-run impact matrix of the VECM for the cointegrating vector of reaction variables do not indicate any asymmetric adjustment for inflation and output. However, there is asymmetric error-correction behavior for monetary policy that suggests regime dependence with adjustment only in the low-variance regime.

The following section outlines the cointegrated VAR or VECM and the Markov-switching (MS) technique for the VECM. Section 3 discusses the data and the preliminary specification of the models. Section 4 presents the estimation results and impulse response functions for the 1-regime cointegrated VAR and the results for the 2-regime MS-VECM. The final section briefly discusses the implication of the results for future monetary policy and research.

\section{Empirical Methodology}

Identification of the empirical model proceeds in two steps. First, the cointegrating properties and long-run relationships are identified in a linear VECM. The cointegrating properties for the linear model are derived using the well-established maximum likelihood procedure developed by Johansen (1996) for the long-term properties for linear systems. Second, the properties and the long-run relationships are imposed on to the regime-switching model where the short-run effects are identified through the contemporaneous impact matrix.

The linear cointegrated vector autoregression or VECM for q variables and p lags may be written as

$$
\Delta y_{t}=\sum_{i=1}^{p-1} \Gamma_{i} \Delta y_{t-i}+\Pi_{t} Y_{t-1}+\varepsilon_{t}
$$

where $\Delta \mathrm{y}_{\mathrm{t}}=\left[\Delta \mathrm{y}_{1 \mathrm{t}}, \Delta \mathrm{y}_{2 \mathrm{t}}, \ldots, \Delta \mathrm{y}_{\mathrm{qt}}\right]^{\prime}$ is a $\mathrm{q}$-dimensional vector of differenced time series for $\mathrm{t}=1, \ldots \mathrm{T}, \Gamma_{\mathrm{i}}$ 's is a $\mathrm{q} \times \mathrm{q}$ matrix of $\mathrm{p}$-order autoregressive parameters that denote the 
short-run dynamics of the model, and $\varepsilon_{\mathrm{t}}=\left[\varepsilon_{1 \mathrm{t}}, \varepsilon_{2 \mathrm{t}}, \ldots, \varepsilon_{\mathrm{qt}}\right]^{\prime}$ is a q- dimensional vector of Gaussian white noise processes for a covariance matrix $\Sigma_{t}, \Pi_{t}$ is the long-run impact matrix defined by $\mathrm{r} x \mathrm{q}$ matrix of cointegrating vectors, $\beta$, and the q x r weighting matrix, $\alpha_{\mathrm{t}}$, where $r$ is the dimension or rank of the cointegration vector. The rank $\Pi_{t}=r$ can be interpreted as the number of stationary relations. Thus, for the linear VECM in equation (1), the long-run impact matrix is

$$
\Pi_{\mathrm{t}}=\alpha_{t} \beta^{\prime}
$$

The model in equations (1) and (2) can be extended to include regime-dependent coefficients and covariance matrix given these cointegrating properties, with the underlying assumptions of time-invariance of the cointegrating relationship and of time-series processes with no changes in structure. Saikkonen and Luukkonen (1997) show that these procedures originally developed for finite Gaussian VAR systems can be employed when the data are generated by an infinite non-Gaussian VAR and provide consistent estimates for the cointegrating vectors even in the presence of regime-switching.

An important characteristic of the MS-VECM (p) is that the contemporaneous covariance matrix of the residuals is also regime switching, and substantial differences across regimes emerge in the estimation, especially for the monetary policy rate. Consequently, the $\varepsilon_{\mathrm{t}}=\left[\varepsilon_{1 \mathrm{t}}, \varepsilon_{2 \mathrm{t}}, \ldots, \varepsilon_{\mathrm{qt}}\right]^{\prime}$ in equation (1) is a q-dimensional vector of Gaussian white noise processes for each regime i with covariance matrix $\Sigma_{t}$ conditioned on $s_{t}$,

$$
\varepsilon^{\sim N} \operatorname{NID}\left(0, \Sigma\left(s_{t}\right)\right)
$$

The long-run impact matrix $\Pi_{t}$ in equation (2) is also state-dependent. The regime-switching $\operatorname{in} \Pi\left(s_{t}\right)$ can be interpreted as switching in the cointegrating vector, the weighting matrix, or both. Preliminary testing indicated that the long-run impact matrices could be defined by the $(r \times q)$ matrix of the state-independent cointegrating vector $\beta$ and the $(q x r)$ state-dependent weighting matrix $\alpha\left(\mathrm{s}_{\mathrm{t}}\right)$. In other words, $\beta$ represents the coefficients of the long-run effects that do not change over the entire sample period and $\alpha\left(s_{t}\right)$ stands for the regime-dependent adjustment coefficient that controls how the endogenous variables respond to the disequilibria represented by the r-dimensional stationary vector $\beta^{\prime} \mathrm{Y}_{\mathrm{t}-1}$. Consequently, equation (2) can be written as

$$
\Pi\left(s_{\mathrm{t}}\right)=\alpha\left(s_{\mathrm{t}}\right) \beta^{\prime}
$$

The description of the data-generation process is not completed by the observational equations (1), (3) and (4). A model for the regime-generating process is needed to allow for inference about the evolution of the regimes from the data. The special characteristic of the Markov-switching model is the assumption that the unobservable realization of regime $s_{\mathrm{t}} \in\{1, \ldots, \mathrm{m}\}$ is governed by an unobserved discrete-time, discrete-state Markov stochastic process. Formally, the stochastic process is defined by the transition probabilities

$$
P_{i j}=\operatorname{Pr}\left(s_{t+1}=j \mid s_{t}=i\right), \sum_{j=1}^{m} P_{i j}=1 \forall i, j \in\{1, \ldots, m\} .
$$


The Markov property described in equation (5) says that the probability of a state $\mathrm{m}$ at time $\mathrm{t}$, i.e. $s_{t}=m$, only depends on the state in the previous period, $s_{t-1}$. More specifically, $s_{t}$ is assumed to follow an ergodic and irreducible m-state Markov chain of order one with the transition matrix

$$
\mathrm{P}=\left[\begin{array}{cccc}
\mathrm{P}_{11} & \mathrm{P}_{12} & \ldots & \mathrm{P}_{1 \mathrm{~m}} \\
\mathrm{P}_{21} & \mathrm{P}_{22} & \ldots & \mathrm{P}_{2 \mathrm{~m}} \\
\ldots & \ldots \ldots & \ldots & \ldots \\
\mathrm{P}_{\mathrm{m} 1} & \mathrm{P}_{\mathrm{m} 2} & \ldots & \mathrm{P}_{\mathrm{mm}}
\end{array}\right],
$$

where $\mathrm{p}_{\mathrm{im}}=1-\mathrm{p}_{\mathrm{i} 1}-\cdots-\mathrm{p}_{\mathrm{i}, \mathrm{m}-1}$ for $\mathrm{i}=1, \ldots, \mathrm{m}$. By inferring the probabilities of the unobserved regimes conditional on an available data set, it is then possible to reconstruct the regimes. For an ergodic Markov chain, regime shifts are persistent if $\mathrm{p}_{\mathrm{ij}} \neq \mathrm{p}_{\mathrm{ii}}$ for $\mathrm{i} \neq \mathrm{j}$ and not absorbing or permanent if $\mathrm{P}_{\mathrm{ii}} \neq 1$ for all $\mathrm{i}$. In this class of models, the regime that prevails at time $t$ is unobservable. The transition probability $p_{i j}$ says how likely state $i$ will be followed by state $\mathrm{j}$.

The two components of the MSH(m)-VECM(p) model, in the terminology of Krolzig (1997), the Gaussian multivariate model (1), (3) and (4) as the conditional data generating process, and the Markov chain (5) as the regime generating process, are estimated using a likelihood-based statistical method. The maximization of the likelihood function of the MS-VECM entails an iterative technique to obtain estimates of the error-correction matrix $\alpha\left(s_{t}\right)$ and variance-covariance matrices $\Sigma\left(s_{t}\right)$ and the transition probabilities $p_{i j}$ governing the Markov chain of the unobserved states. The maximum likelihood method faces two important practical difficulties. First, the global maximum of the likelihood function may prove difficult to locate. Second, the likelihood function for the important class of mixtures of normal distributions is not bounded and the maximum likelihood estimator does not exist for the global maximum.

The more commonly used method of estimation for the MS models is the Expectation Maximization (EM) algorithm originally proposed by Hamilton (1990) for this class of models. Assuming a normal conditional distribution of $\mathrm{Y}_{\mathrm{t}}$, the likelihood function is numerically approximated in two steps. The expectation step involves a pass through the smoothing algorithm, using the estimated parameter vector for the VAR of the last maximization step in place of the unknown true parameter vector to infer the hidden Markov chain. In the maximization step, an estimate of the parameter vector is derived as a solution of the first-order conditions of the likelihood function, where the conditional regime probabilities are replaced with the smoothed probabilities derived in the last expectation step. These two steps are repeated until convergence is achieved for the maximum likelihood function. The switches between different states are not accounted as deterministic occurrences, but are assumed to follow an exogenous stochastic process. Since the EM algorithm cannot directly compute the standard errors of the parameters, a few subsequent iterations of the maximum likelihood estimator are then used to estimate the standard errors. 


\section{Data and Preliminary Specification}

\subsection{Data}

The estimation period is from 1972:1 to 2016:4 and the frequency is quarterly.(Note 1) The domestic macroeconomic variables for the estimations include the overnight financing rate (policy) as the monetary policy rate, (Note 2) the log of GDP in 2002 chain-linked dollars (output), and the inflation rate (inflation). (Note 3) The inflation rate is the log-difference of consumer the price index for all items over four quarters and scaled by 100 so that changes can be interpreted as the 4-quarter percentage change, consistent with the specification of the current inflation targets in Canada. The log of real GDP is multiplied by 100 so that a change can be interpreted as a percentage and the policy interest rate is in per cent.

The external macroeconomic variables include the logs of the real exchange rate (pfx) and the real commodity price index (pcom). The real exchange rate is defined as the Canada-U.S. nominal exchange rate (e.g., price of a unit of U.S. currency in terms of Canadian currency) multiplied by the ratio of the U.S. GDP deflator to the Canadian GDP deflator. The real commodity price index is the nominal index divided by GDP deflator. The logs of the real exchange rate and the real commodity price index are also multiplied by 100 . The real exchange rate is included as a policy reaction variable because of the Bank of Canada's use of the Monetary Conditions Index (MCI) as an operational target beginning in the late 1980s. (Note 4) Monetary policy in Canada at times has responded to disturbances in the foreign exchange market to maintain a stable exchange-rate environment or a particular level of monetary conditions. Clarida et al. (1998), for example, also suggest lagged values of the exchange rate as possible variables in the central bank's information set at the time it chooses the interest rate. Lange (2013) finds evidence of an important role for the real exchange rate in a contemporaneous policy-reaction function for Canada during certain periods.

The real index of commodity prices is included in the model because Canada as a resource-oriented economy relies on commodity prices that are determined in global markets as some indication of future economic growth. In addition, commodity prices are often included in VARs because they serve as information that is available to the central bank about supply disturbances as possible sources of future inflation. In fact, Sims (1992) recommends including commodity prices in identified VAR models to diminish or eliminate the now familiar 'price puzzle,' where an unexpected monetary tightening leads to an increase rather than a decrease in the price level or inflation. Consequently, the data vector for the domestic and external reaction-policy variables in the cointegrated vector autoregressive model are given by

$$
\left.\mathrm{Y}_{\mathrm{t}}=\text { (Output }_{\mathrm{t}} \text { Inflation }_{\mathrm{t}}, \text { Policy }_{\mathrm{t}_{\mathrm{n}}}, \mathrm{Pfx}_{\mathrm{t}}^{*}, \mathrm{Pcom}_{\mathrm{t}}^{*}\right)
$$

where * indicates that the reaction variables cannot be excluded from the cointegration vector but can be restricted to being weakly exogenous, as expected with variables that are largely determined in external auction markets. 


\subsection{Preliminary Specification}

The choice of lag length for the VAR was guided by the Akaike Information, Schwarz Bayesian and Hannan-Quinn Criteria, and sequential likelihood-ratio tests from 0 to 4 lags presented in Table 1. The likelihood-ratio test chooses 3 lags and the information criteria choose 2, 1 and 2 lags, respectively. Consequently, 2 lags are considered to be the appropriate choice.

Table 1. Tests of Lag Length

\begin{tabular}{lllll}
\hline lag & AIC & SBC & HQC & LR test \\
\hline 0 & 34.45 & 34.54 & 34.48 & $\ldots$ \\
1 & 18.12 & $\mathbf{1 8 . 6 5}$ & 18.33 & 0.000 \\
2 & $\mathbf{1 7 . 7 8}$ & 18.72 & $\mathbf{1 8 . 1 4}$ & 0.000 \\
3 & 17.86 & 19.21 & 18.35 & 0.000 \\
4 & 18.00 & 19.73 & 18.60 & $\mathbf{0 . 1 6 6}$ \\
\hline
\end{tabular}

Note: AIC is the Akaike Information Criterion, SBC is Schwarz Bayesian Criterion, HQC is the Hannan-Quinn criterion, LR test is the p-values for sequential likelihood ratio tests, and bold is for lowest values for AIC, SBC and HQC and the LR test for significance at the 5\% level.

Table 2 presents the augmented Dickey-Fuller tests for a unit root. The null hypothesis of non-stationarity cannot be rejected for all policy reaction variables with two lags at all conventional levels of significance.

Table 2. Dickey-Fuller t-statistics for unit root tests for the cointegration policy variables

\begin{tabular}{ccccc}
\hline Output Level & Inflation Rate & Policy Rate & Real PFX Level & Real PCOM Level \\
\hline-2.90 & -1.93 & -1.42 & -1.99 & -1.85 \\
(trend/constant) & (constant) & (constant) & (constant) & (constant) \\
\hline
\end{tabular}

Note: $\quad$ significance levels are $-3.47(1 \%),-2.88(5 \%),-2.58(10 \%)$ with a constant and -4.01 $(1 \%),-3.44(5 \%),-3.14$ (10\% with both a constant and trend.

\section{Estimation Results}

\subsection{Cointegration Relationship}

Table 3 presents the estimated values of the characteristic roots or eigenvalues and the trace statistics for the cointegration relationship for the policy variables in equation (7) using the Johansen (1996) maximum likelihood estimation procedure. The trace statistic is calculated as 


$$
\operatorname{Trace}(r)=-T \sum_{i=r+1}^{p} \ln \left(1-\lambda_{i}\right),
$$

where $\lambda_{i}$ is eigenvalue $\mathrm{i}, \mathrm{p}$ is the full-rank number of unit roots, and $\mathrm{r}$ is the dimension of the cointegration vector. The $\lambda_{\text {trace }}$ statistics are displayed for the null hypothesis of $r=0,1,2$, along with critical values for the $95 \%$ significance level.(Note 5). The null hypothesis that the policy variables are not cointegrated $(\mathrm{r}=0)$ against the alternative of one or more cointegrating vectors $(r>0)$ is easily rejected since trace statistic is greater than the critical value. The null hypothesis of $r \leq 1$ against the alternative of two or more cointegrating vectors is also rejected on the basis of a critical value of 30.78 for the trace statistic with a marginal significant level (p-value) equal to 0.10 . The Bartlett corrected trace test for small sample size developed by Johansen (2002), which has the effect of lowering the estimated value of the trace statistic and making it harder to reject the null hypothesis of p-r unit roots, also cannot reject $r=1$ and two unit roots with a p-value of 0.44 . Hence, the rank tests suggest the system contains two common trends and one cointegrating relation.

Table 3. Cointegration Vector

\begin{tabular}{lllllllll}
\hline $\mathrm{p}-\mathrm{r}$ & $\mathrm{r}$ & $\mathrm{i}$ & Eigenvalue & Trace & Trace* $^{*}$ & Trace95\% & P-value & P-value* \\
\hline 3 & 0 & 1 & 0.339 & 100.95 & 96.37 & 49.96 & 0.00 & 0.00 \\
2 & 1 & 2 & 0.102 & 27.79 & 20.22 & 30.78 & 0.10 & 0.44 \\
1 & 2 & 3 & 0.048 & 8.73 & 6.39 & 15.25 & 0.37 & 0.61 \\
\hline
\end{tabular}

Note: $p-r$ is the number of unit roots, $r$ is rank, $i$ is for the eigenvalue $\left(\lambda_{1}\right)$ in the calculation of trace statistic, Trace is the trace statistic, Trace* is the small sample corrected trace statistic, Trace $95 \%$ is $5 \%$ critical value of the null hypothesis of $\mathrm{H}(\mathrm{r})$ against the alternative hypothesis of $\mathrm{H}(\mathrm{p})$, and the $\mathrm{p}$-value is for the uncorrected trace test and p-value* for the corrected trace test.

Table 4 presents the one cointegration vector that spans the cointegration space for the policy variables. Although the variables in the cointegration vector are monetary policy reaction variables, the vector should not be directly interpreted as a policy reaction function.(Note 6) For example, the bottom two panels present the normalizations on the inflation and monetary policy rates, respectively, where they can be interpreted as dependent variables in equations for inflation and the monetary policy rate. The unrestricted cointegration vector suggests that inflation and the policy rate are negatively related to each other and to the level of output. However, the effects of the variables in the equations will depend on the signs of the error-correction coefficients ( $\alpha$ s) in the equations of the model. In conjunction with the error-correction terms it is possible to make an interpretation that gives a picture of the long-run information in the data. Since the sum of the coefficients including the intercept in the restricted and unrestricted cointegration vectors are negative, the error-correction terms $(\alpha s)$ that are also negative in the equations with short-run dynamics will indicate that the 
cointegration relation is overshooting in those equations. Similarly, when $\beta$ and $\alpha$ are of the opposite sign, the cointegration relation will suggest equilibrium or error correcting behaviour.

Table 4. Cointegration Vector

\begin{tabular}{lllllll}
\hline Vector & Output Level & Inflation Rate & Policy Rate & Real Pfx & Real Pcom & Intercept \\
\hline Unrestricted & -0.031 & -0.325 & -0.121 & 0.032 & 0.016 & -1.406 \\
Restricted & 0.130 & $\mathbf{1 . 0 0 0}$ & 0.505 & -0.134 & -0.066 & -5.885 \\
& $(5.57)$ & $(\mathrm{n} / \mathrm{a})$ & $(2.93)$ & $(2.49)$ & $(2.44)$ & $(1.17)$ \\
Restricted & 0.258 & 1.980 & 1.000 & -0.264 & -0.131 & -11.594 \\
& $(5.23)$ & $(3.01)$ & $(\mathrm{n} / \mathrm{a})$ & $(2.39)$ & $(1.90)_{-}$ & $(0.99)$ \\
\hline
\end{tabular}

Note: Restricted vectors indicate normalization with a value of 1.0 in bold and t-statistics in brackets.

Figure 1 presents the residuals of the unrestricted cointegration vector corrected for short-run dynamics. The relation looks stationary around a mean of zero. There is no trend in the cointegrating relation, as indicated in Table 2 neither the interest rate, inflation, the real exchange rate or real commodity price should contain deterministic trends that require a trend term in the cointegrating space.

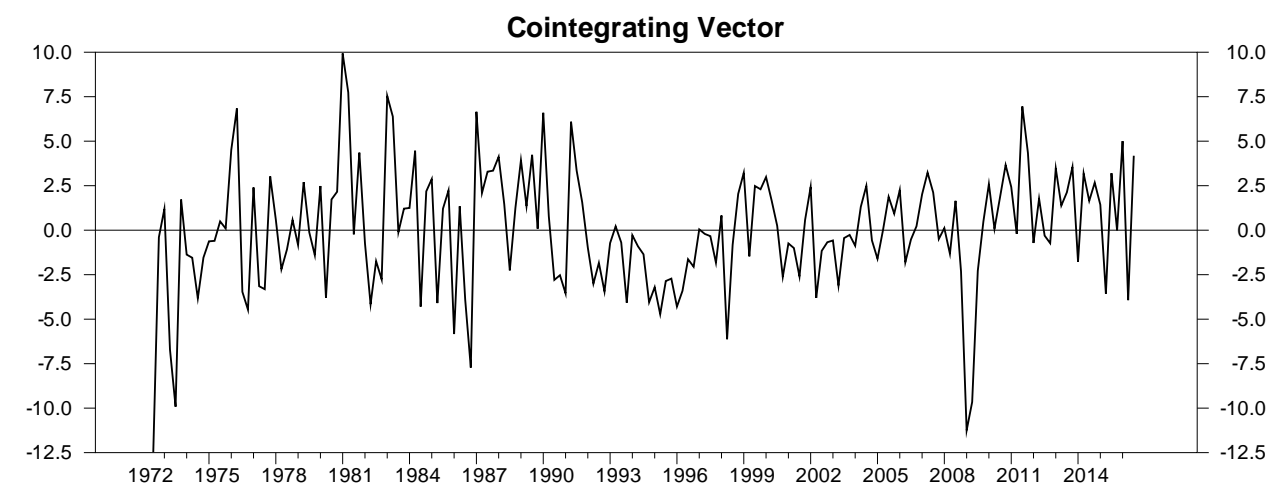

Figure 1. Cointegrating Vector for the Domestic and External Policy Variables in Table 4

Figure 2 presents the test statistics for a recursive estimation of the linear model, where the cointegrating vector $\beta$ is fixed at the full sample estimate. The test statistic is scaled by the 5 -per cent critical value such that a value larger than unity indicates a significant test statistic. Overall, the recursive estimation suggests some instability in the coefficients for the short-run dynamics at times until about 1979-80, but that in general the error-correction and cointegration coefficients have been relatively stable over the sample period beyond that point as assumed in the estimations. As pointed out by Francis and Owyang (2005) this relative stability in the long-run coefficients may partially characterize a solution to the 
rational expectations critique of policy coefficients.

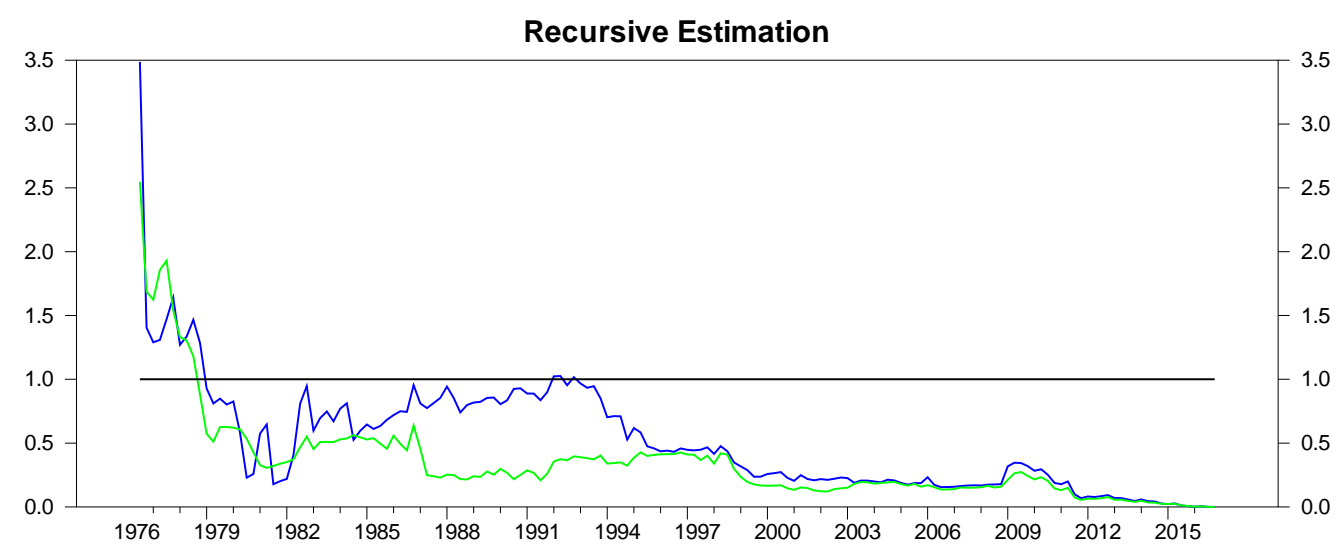

Figure 2. Recursive estimations for all parameters in the VECM (blue) and only the long-run error-correction and cointegration parameters with the short-run dynamics concentrated (green)

\subsection{Impulse Responses}

The impulse responses for the linear cointegrated VAR model with the unrestricted vector of policy reaction variables in Table 4 are presented in Figure 3. The confidence bands for the impulse responses are presented as the fractiles 0.16 and 0.84.(Note 7) Since the estimated VECM includes a weakly exogenous variable, the real price of commodities,(Note 8) the conditional posterior distributions for the confidence intervals do not have convenient Monte Carlo properties. Consequently, the intervals are computed using the Bayesian method suggested by Gelfand and Smith (1990), which uses a Markov Chain Monte Carlo (MCMC) algorithm to deal with the posterior distribution. The Bayesian MCMC parameter estimation are based on the Gibbs sampling, which generates a Markov chain of samples of observations that can approximate the joint probability distribution of the random variables in the model. Since each sample is correlated with nearby samples, the samples from the beginning of the chain, called the "burn-in period," may not accurately represent the desired unconditional distribution. Consequently, a certain number of the early random draws of the covariance matrix from estimated VECM are dropped out of the 10,000 simulations used to obtain the unconditional posterior distribution in the limit. The confidence bands are displayed around the mean of the drawn responses for the impulse response functions, where "significant" for a response means statistically different from zero, which corresponds to the case where the error confidence bands of the response function lie on one side of the $\mathrm{x}$-axis. The graphs in each row are standardized to ensure that small responses are not inflated.

The impulse responses for a 1-standard deviation shock to the exogenous real price of commodities (PCOM) in the first column indicates that both output and inflation initially increase, monetary policy responds by raising the overnight interest rate, and the real exchange rate appreciates (decrease in the price of foreign currency). An innovation in output increases the inflation rate and the policy rate responds by increasing over most of the 


\section{MlMacrothink}

forecast horizon. Similarly, the monetary policy rate increases in response to a 1-standard deviation shock to the inflation rate. A monetary policy contraction triggers a recession with a decrease in output. However, there is not a significant decrease in inflation, which is some indication of a 'price puzzle' despite the inclusion of the real price of commodities. A depreciation in the real exchange rate (increase) leads to an increase in output that is significant over the forecast horizon and an increase in the monetary policy rate, although the increase is not significant. Overall, the vector responses of the linear VECM are in line with a conventional policy model of a small open economy.
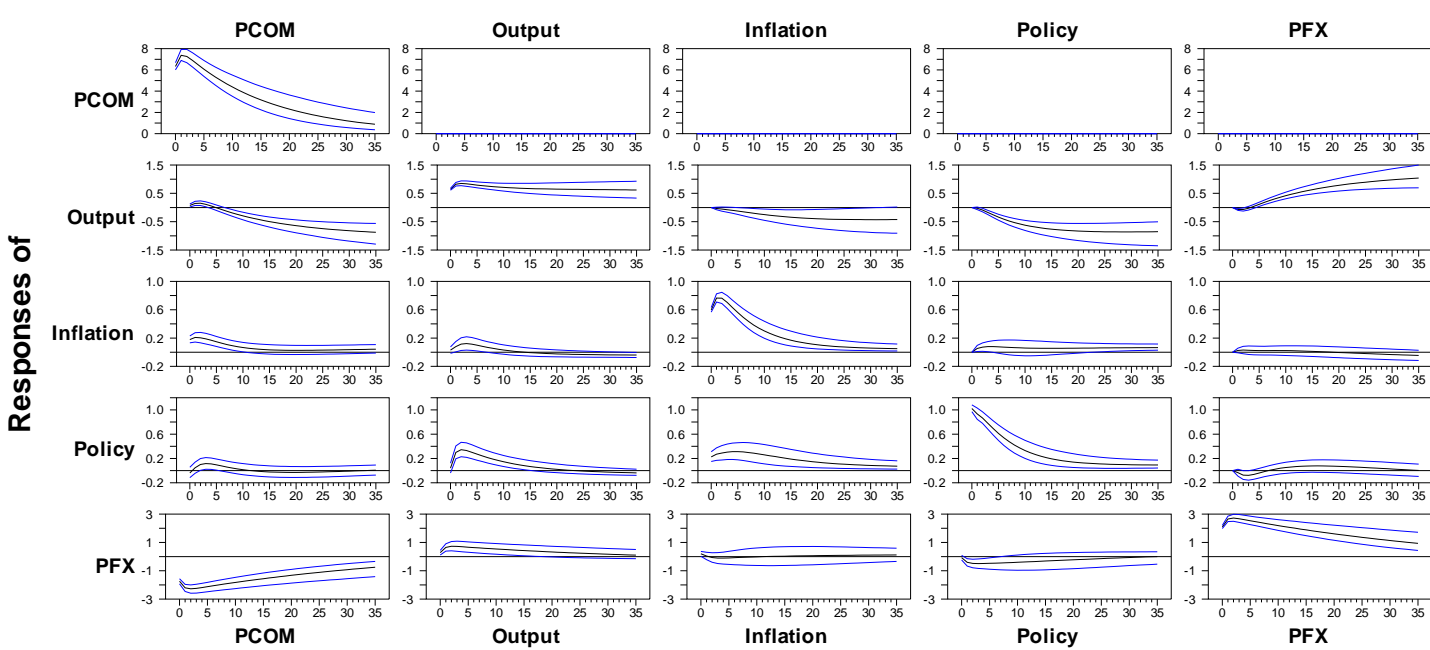

Figure 3. Impulse Responses

\subsection{Macroeconomic Regimes}

The recursive estimation in Figure 2 suggests some instability in the coefficients of the linear model, especially up until about 1979-80. Consequently, the model was re-estimated using the Markov-switching vector error-correction autoregressive model outlined in Section 2. Only the error-correction coefficients and the variances are allowed to switch between regimes. Figure 4 presents the smoothed probabilities for regime switches in the Canadian macroeconomy over the sample period. The Markov-switching estimates stochastically divide the sample period generally into two broad regimes in about 1996. (Note 9) The low-variance regime 1 is virtuously continuous from 1996 to 2016, with high-variance regimes only occurring during economic downturns in the early-2000s and during the Great Recession in 2008-09. The 1972-95 period is also virtuously continuous. It essentially corresponds to the oil-price shocks in the early- and late-1970s, the mid-1980s when the Canadian economy experience some weak growth and downturns, and again in the early1990s when aggressive monetary policy was pursued following the adoption of explicit inflation targets in 1991.

Figure 4 indicates that the regimes are well classified with probabilities being relatively close to zero or one. The quality of the regime classification may be confirmed by the following the regime classification measure (RCM) proposed by Ang and Bekaert (2002) for m states 


$$
\operatorname{RCM}=100 \mathrm{~m}^{2} \frac{1}{\mathrm{~T}} \sum_{\mathrm{t}=1}^{\mathrm{T}}\left(\prod_{\mathrm{i}=1}^{\mathrm{m}} \mathrm{p}_{\mathrm{i}, \mathrm{t}}\right),
$$

where $\mathrm{p}_{\mathrm{i}, \mathrm{t}}=\mathrm{p}\left(\mathrm{s}_{\mathrm{t}}=\mathrm{i} \mid \mathrm{Y}_{\mathrm{T}}\right)$ is the ex-ante smoothed (unconditional) probability of being in regime $\mathrm{i}$. The constant 400 for two regimes serves to normalize the statistic to be between 0 and 100. A good regime classification is associated with a low RCM value, with zero being a perfect classification and 100 implying that no information is revealed about the regimes. The RCM for the VECM regime-switching estimation presented in Figure 4 is 17.29, indicating that the regimes are very well classified and the model is well specified.(Note 10)

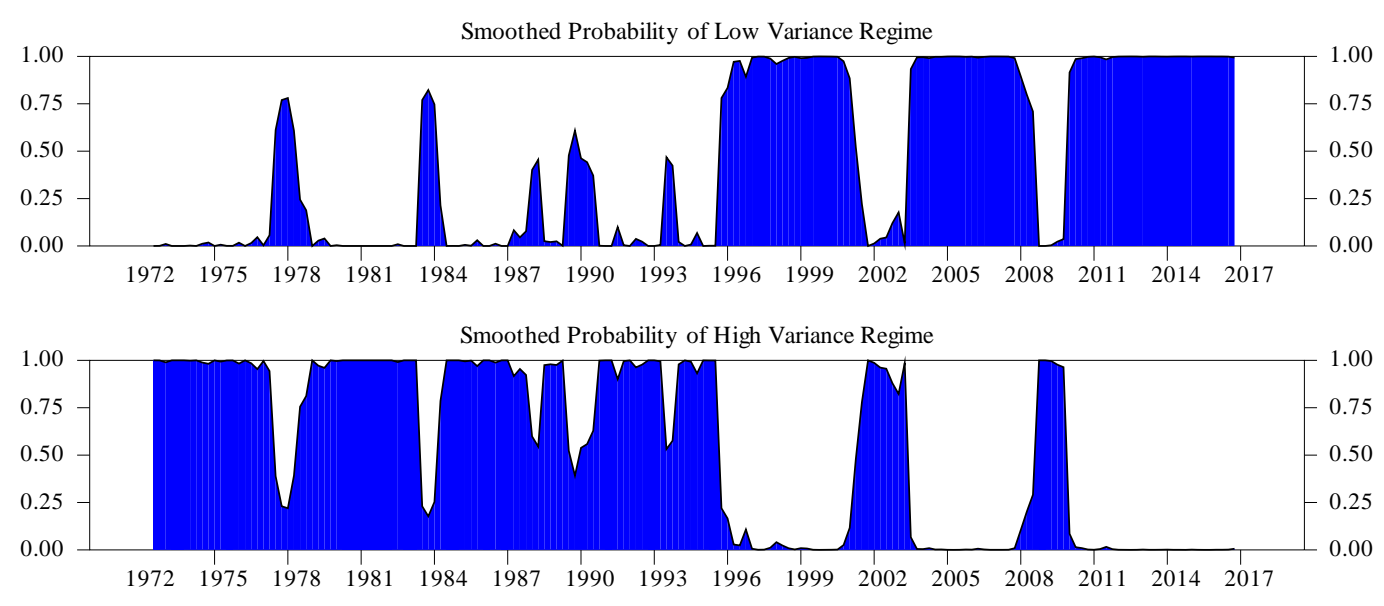

Figure 4. Smoothed Filtered Probabilities for the 2-regime Estimation

\subsection{Markov-Switching Results}

Preliminary estimation revealed that the logs of the real exchange rate and the price of the real commodity price index should be include in the cointegration vector, but that the error-correction terms ( $\alpha$ s) should be excluded from the short-run dynamics for those variables since they could easily be restricted to equal zero. Consequently, these variables were treated as being weakly exogenous in the estimations.

The regime properties for the smoothed probabilities in Figure 4 are presented in Table 5. The (stationary) transition probability matrix indicates that the regimes are quite persistent, with small probabilities of switching to another regime. The number observations with regime probabilities greater 0.5 than indicate ergodic probabilities (long-run average probabilities of the Markov process) of about 45 per cent for regime 1 and 55 per cent for regime 2 . The average expected duration $\left(1 / 1-\mathrm{p}_{\mathrm{ii}}\right)$ is slightly over 3 years or 12.5 quarters for regime 1 , and $21 / 2$ years or 14.3 quarters for regime 2 . 
Table 5. Macroeconomic Regime Properties

\begin{tabular}{lllll}
\hline Regime & Transition Probabilities & Observations & Ergodic Probabilities & Duration \\
\hline 1 & $\mathrm{p}_{11}=0.92 \mathrm{p}_{21}=0.08$ & 80 & 0.45 & 12.50 \\
2 & $\mathrm{p}_{22}=0.93 \mathrm{p}_{12}=0.07$ & 98 & 0.55 & 14.29 \\
\hline
\end{tabular}

Note: $\mathrm{p}_{\mathrm{ii}}$ is the transition probability for regime $\mathrm{i}=1$, 2 , observations is the number of observations in regime $\mathrm{i}$ with $\mathrm{p}_{\mathrm{ii}}>0.5$ and duration is the expected duration (quarters) of regime $\mathrm{i}$ calculated as duration $=\left(1 / 1-\mathrm{p}_{\mathrm{ii}}\right)$ based on estimates using the $\mathrm{EM}$ algorithm.

The estimation results for the error-correction terms and the variances for the log of real GDP, the inflation rate and the monetary policy rate for both the 1-regime and the 2-regime, Markov-switching models are presented in Table 6. In the top panel, the maximum of the likelihood function obtained from the MS (2)-VECM (2) is substantially higher than that from the linear VECM (2). The maximum log likelihood function can be interpreted as a measure of the model's goodness of fit since the maximum likelihood estimator represents the value of the model's parameters for which the sample is most likely to have been observed. The Likelihood Ratio (LR) test under normal conditions does not apply here due to the existence of unidentified nuisance parameters (the transition probabilities are not identified under the linear model). To circumvent this problem, the LR test statistic is compared to a $x^{2}(d+n)$ distribution where $d$ denotes the number of degrees of freedom including the variance-covariance matrix of residuals (restrictions) and $\mathrm{n}$ stands for the number of nuisance parameters for the transition probabilities $\left(\mathrm{p}_{\mathrm{ii}}\right)$. (Note 11) Since the test statistic exceeds the critical value under this benchmark, the null hypothesis of a linear VECM can be rejected at very high significance levels and a nonlinear regime-switching specification is superior to the linear specification.

The variances for the regime-switching estimations in the middle panels reveal that the lowand high-variance regimes in Figure 4 can be attributed to the shifts in the variances of the ( $\log$ ) of real GDP, the inflation rate and the monetary policy rate. The estimation mainly identifies two distinct regimes that differ mostly with respect to interest rate volatility. The huge jump in the variance for the policy rate in regime 2 is most notable and reflects the very large increases in interest rates that were required in regime 2 to offset the effects on inflation triggered by the oil price shocks during the 1970s and early-1980s, as well as the large increase in the early-1990s following the formal adoption of explicit inflation targets in 1991. These estimates for the conditional variances of the policy rate reveal considerable differences in the levels of within-regime volatility between the low- and high- variance regimes, confirming the well-known evidence of heteroskedasticity of short-term interest rates. Overall, the regime-switching estimation captures conditional heteroskedasticity in the form of Markov switching in the scale of the variances, where the error terms of the equations for the policy rate, the inflation rate and the level of output switch discretely between low- and high-variance regimes. 


\section{Mll Macrothink}

Table 6. Estimates for the 1- and 2-Regime Vector Error-Correction Models

\begin{tabular}{|c|c|c|c|c|c|c|}
\hline \multirow{5}{*}{ LLF } & \multicolumn{3}{|c|}{ 1-Regime Model } & \multicolumn{3}{|c|}{ 2-Regime-Switching Model } \\
\hline & \multicolumn{3}{|c|}{$-1,544.32$} & \multicolumn{3}{|c|}{-514.78} \\
\hline & \multicolumn{3}{|c|}{ LR Linearity Test } & \multicolumn{3}{|c|}{ P-value } \\
\hline & \multicolumn{3}{|c|}{ Statistic $=2,059.08$} & \multicolumn{3}{|c|}{$\chi^{2}(11)=0.00$} \\
\hline & Policy Rate & Inflation & Output Level & Policy Rate & Inflation & Output Level \\
\hline \multirow{2}{*}{$\sigma_{1}^{2}$} & \multirow{2}{*}{1.09} & \multirow{2}{*}{0.388} & \multirow{2}{*}{0.379} & 0.072 & 0.192 & 0.137 \\
\hline & & & & $(6.44)$ & $(6.41)$ & $(5.87)$ \\
\hline \multirow{2}{*}{$\sigma_{2}^{2}$} & \multirow{2}{*}{---- } & \multirow{2}{*}{----} & \multirow{2}{*}{----} & 2.239 & 0.565 & 0.582 \\
\hline & & & & $(6.36)$ & $(7.35)$ & $(6.24)$ \\
\hline \multirow[b]{2}{*}{$\alpha_{1}$} & 0.177 & -0.047 & -0.406 & 0.098 & -0.051 & -0.463 \\
\hline & $(2.22)$ & $(-0.90)$ & $(-8.63)$ & $(4.44)$ & $(-1.49)$ & $(-15.90)$ \\
\hline \multirow{2}{*}{$\alpha_{2}$} & \multirow{2}{*}{----} & \multirow[t]{2}{*}{---- } & \multirow[t]{2}{*}{----} & 0.004 & -0.061 & -0.380 \\
\hline & & & & $(0.04)$ & $(-1.26)$ & $(-8.36)$ \\
\hline
\end{tabular}

Note: LLF is the log likelihood function. The Likelihood Ratio (LR) test of the linear model against the Markov switching alternative is computed as LR=2 $x(\ln \operatorname{LMS}(2)-\operatorname{VECM}(2)-\ln$ LVECM (2)), where L denotes the value of the likelihood function under the respective models. The test statistic is $\chi^{2}$ distributed with the degrees of freedom corrected for the unidentified nuisance parameters for $\sum_{i=1}^{2} p_{i i}=2$. The marginal significance level is denoted by the $\mathrm{p}$-value. The error-correction coefficient for the cointegrated policy variables in regime $i=1,2$ is $\alpha_{i}$ and $\sigma_{i}^{2}$ is the variance for the variables in regime $i=1,2$ that are not weakly exogenous. Figures in parentheses are t-statistics based on standard errors of the maximum function value.

The estimation results for the error-correction coefficients ( $\alpha s)$ in the bottom panels indicate that the size of the coefficients in the equations for inflation and output are about the same size in both regimes and about the same size as the coefficients in the 1-regime linear model. This does not indicate any asymmetric behaviour on the part of inflation or output. Also, the sign of the coefficients in the short-run dynamics for these variables in both the 1- and 2-regime estimations are negative, indicating over-correcting behaviour. However, the sign of the coefficients in the short-run dynamics for the monetary policy rate are positive in both the 1- and 2-regime estimations. Since the sum of the coefficients in the cointegration vector for the monetary policy are negative, this suggests, as discussed above, that monetary policy in general error-corrects for movements in inflation and output. The most interesting result is the asymmetry in the error-correction coefficients for the monetary policy rate, which show a Markovian shift in the adjustment parameter to short-run deviations from the long-run equilibrium relationship only in the current low-variance regime 1 since the error-correction coefficient is insignificant in the high-variance regime 2. Consequently, the significant positive sign indicates asymmetric and error-correction behaviour on the part of monetary policy only in the low-variance regime 1. Overall, estimated coefficients in Table 6 suggest that rejection of the linear VECM in favour of the nonlinear MS-VECM can be attributed 
mainly to the variance-covariance matrix of residuals.

\section{Concluding Remarks}

This study identifies the existence of a long-run equilibrium relationship among important information variables for monetary policy in Canada. A single cointegrating vector of policy reaction variables for both the domestic macroeconomy and external disturbances is found to be quite stable. The regime-switching estimations capture two stochastic policy regimes with low- and high-variances. Following Hamilton (1989), the generating mechanism of these shifts was modeled as a finite-state Markov process with an unknown (but stationary) transition mechanism. The long-run impact matrices of the vector error-correction model for the cointegrating vector of policy reactions did not uncover any asymmetric adjustments for inflation and output. However, the error-correction adjustment for monetary policy is found to exist only in the low-variance regime. In general, there is no significant evidence in favour of time-varying cointegration where the long-run parameters are allowed to switch stochastically between two different cointegrating regimes.

The results from this study suggest a current macroeconomic regime with the lower volatility in interest rates, inflation and output that began in about 1996. The low-variance regime is likely a permanent shift in monetary policy behaviour that can be attributed to the adoption of explicit inflation targets, as found by Lange (2016). Consequently, monetary policy will continue to operate with a stable reaction function and error corrections for any needed policy adjustments.

Future research with the error-correction and regime-switching framework could focus on information variables for monetary policy related to financial markets. The recent research by Clarida, Sarno, Taylor, and Valente (2006) on the term structure of interest rates and by Bjornland and Leitemo (2008) on the stock market would be useful starting points.

\section{References}

Ang, A., \& Bekaert, G. (2002). Regime switches in interest rates. The Journal of Business and Economics, 20, 163-182. http://dx.doi:10.3386/w6508

Armour, J., Engert, W., \& Fung, B. (1996). Overnight innovations as a measure of monetary policy shocks in vector autoregressions. Bank of Canada Working Paper, no. 96-4. https://doi.org/10.2139/ssrn.56181

Bernanke, B., \& Mihov, I. (1998). Measuring monetary policy. The Quarterly Review of Economics, 113, 869-902. http://dx.doi.org/10.3386/w5145

Blanchard, O., \& Quah, D. (1989). The dynamic effects of aggregate demand and supply disturbances. The American Economic Review, 79, 655-673. http://dx.doi.org/10.3386/w2737 
Boivin, J., \& Giannoni, M. (2002). Assessing changes in the monetary transmission mechanism: A VAR approach. Federal Reserve Bank of New York, Economic Policy Review, May 97-111.

Bjornland, H., \& Leitemo, K. (2008). Identifying the interdependence between the US monetary policy and the stock market. Journal of Monetary Economics, 56, 275-282. http://dx.doi.org/10.1016/j.jmoneco.2008.12.001

Christiano, L., Eichenbaum, M., \& Evans, C. (1999). Monetary policy shocks: What have we learned and to what end? In M. Woodford and J. Taylor (Eds.), Handbook of Macroeconomics, North Holland.

Christiano, L., Eichenbaum, M., \& Evans, C. (2005). Nominal rigidities and the dynamic effects of a shock to monetary policy. The Journal of Political Economy, 113, 1-45. http://dx.doi.org/10.1016/j.red.2010.01.001

Clarida, R., Gali, J., \& Gertler, M. (1998). Monetary policy rules in practice: some international evidence. The European Economic Review, 42, 1033-1067. https://doi.org/10.1086/500674

Clarida, R., Gali, J., \& Gertler, M., 2000. Monetary policy rules and macroeconomic stability: evidence and some theory. The Quarterly Review of Economics, 115, 147-180. http://dx.doi.org/10.1162/003355300554692

Clarida, R., Sarno, L., Taylor, M., \& Valente, G. (2006). The role of asymmetries and regime shifts in the term structure of interest rates. Journal of Business, 79(3), 1193-1224.

Feedman, C. (1994). The use of indicators and of the monetary conditions index in Canada. In Tomas Balino, Carlo Cottarelli (Eds.), Frameworks for Monetary Stability: Policy Issues and Country Experiences. International Monetary Fund.

Francis, N., \& Owyang, M. (2005). Monetary policy in A Markov-switching vector error-correction model: Implications for the cost of disinflation and the price puzzle. Journal of Business \& Economics Statistics, 23(3), 305-313. http://dx.doi.org/10.1198/073500104000000325

Gali, J. (1992). How well Does the IS-LM Model fit postwar U.S. data? The Quarterly Journal of Economics, 107, 709-738. http://dx.doi.org/10.2307/2118487

Gelfand, A., \& Smith, A., (1990). Sampling-based approaches to calculating marginal densities. The Journal of the American Statistical Association, 85, 398-409.

Hamilton, J. (1989). A new approach to the econometric analysis of nonstationary times series and business cycles. Econometrica, 57, 357-84. https://doi.org/10.2307/1912559

Hamilton, J. (1990). Analysis of time series subject to change in regime. The Journal of Econometrics, 57, 357-384. http://dx.doi:10.1016/0304-4076(90)90093-9

Hall, S. G., Psaradakis, Z., \& Sola, M. (1997). Cointegration and Changes in Regime: The Japanese Consumption Function, Journal of Applied Econometrics, 12, 151-168. 
https://doi.org/10.1002/(SICI)1099-1255(199703

Hubrich, K., \& Tetlow, R. (2015). Financial Stress and Economic Dynamics: The transmission of crises. Journal of Monetary Economics, 70, 100-115. http://dx.doi.org/10.1016/j.jmoneco.2014.09.005

Johansen, S. (1996). Likelihood-Based Inference in Coitegrating Vector Autoregressive Models, (2 $2^{\text {nd }}$ ed.). Oxford: Oxford University Press.

Johansen, S. (2002). A small sample correction for the test of cointegrating rank in the vector autoregressive model. Econometrica, 70, 1929-1961. https://doi.org/10.1111/1468-0262.00358

Juselius, K. (2006). The Cointegration VAR Model: Methodology and Applications. New York: Oxford University Press Inc.

Krolzig, H. (1997). Markov Switching Vector Autoregressions: Modelling, Statistical Inference and Applications to Business Cycle Analysis. Berlin: Springer-Veriag. https://doi.org/10.1007/978-3-642-51684-9

Krolzig, H. (2001). Business cycle measurement in the presence of structural change: international evidence. The International Journal of Forecasting, 17, 349-368. http://dx.doi.org/10.1016/S0169-2070(01)00099-1

Krolzig H., Marcellino, M., \& Mizon, G. (2002). A Markov-Switching Vector Equilibrium Correction Model of the UK Labour Market. Empirical Economics, 27, 233-254.

Lange, R. (2013). Monetary policy reactions and the exchange rate: a regime-switching structural VAR for Canada. International Review of Applied Economics, 27, 612-632. http://dx.doi.org/10.1080/02692171.2012.752446

Lange, R. (2016). The monetary transmission mechanism and inflation targeting: A regime-switching VAR approach for Canada. Applied Economics and Finance, 3(2), 264-280. http://dx.doi.org/10.11114/aef.v3i2.1338

Paolillo, R. M., \& Petragallo, N. (2004). Asymmetries of monetary policy transmission between US and Euro area. Mimeo. Retrieved from http://www.cass.city.ac.uk/data/assets/pdf_file/0005/65174/PaolilloPetragallo.pdf

Paap, R., \& van Dijk, H.K. (2003). Bayes Estimates of Markov Trends in Possibly Cointegrated Series: An Application to U.S. Consumption and Income. Journal of Business \& Economic Statistics, 21, 547-563. https://doi.org/10.1198/073500103288619296

Saikkonen, P., \& Luukkonen, R. (1997). Testing cointegration in infinite order vector autoregressive processes. Journal of Econometrics, 81, 93-126. https://doi.org/10.1016/S0304-4076(97)00036-5

Sims, C. (1980). Macroeconomics and reality. Econometrica, 48, 1-48. https://doi.org/10.2307/1912017 
Sims, C. (1992). Interpreting the macroeconomic time series facts: The effects of monetary policy. European Economic Review, 36(5), 975-1000. https://doi.org/10.1016/0014-2921(92)90041-T

Sims, C., \& Zha, T. (1999). Error bands for impulse responses. Econometrica, 67(5), 1113-1155. https://doi.org/10.1111/1468-0262.00071

Sims, C., \& Zha, T. (2006). Are there regime switches in US monetary policy? The American Economic Review, 96, 54-81. http://www.jstor.org/stable/30034354

Rubio-Ramírez, J-F., Waggoner, D., \& Zha, T. (2005). Markov-switching structural vector autoregressions: Theory and application. Federal Reserve Bank of Atlanta, Working Paper 2005-27.

Smets, F., \& Wouters, R. (2002). An estimated dynamic stochastic general equilibrium model of the Euro area. The Journal of the European Economic Association, 1, 1123-1175. http://dx.doi.org/10.1162/154247603770383415

Tillmann, P. (2007). Inflation regimes in the US term structure of interest rates. Economic Modelling, 24, 203-223. http://dx.doi.org/10.1016/j.econmod.2006.07.001

\section{Notes}

Note 1 . The beginning of the sample coincides with the introduction of flexible exchange rates.

Note 2. Armour et al. (1996) find that innovations in the overnight rate, derived using a Choleski decomposition, were consistent with intended policy actions as described in the Bank of Canada's Annual Reports since the early 1960s.

Note 3. The inflation specification suggests that the log-level of the consumer price index may be $\mathrm{I}(2)$ over relatively short sample periods. The unit root process (stochastic trend) in inflation is due to the periods of high inflation in the 1970s and early-1980s, the medium-inflation period from the mid-1980s to the early-1990s, and the low-inflation period since the adoption of explicit inflation targets in the early 1990s.Conequently, inflation exhibits considerable inertia and persistence over these periods, consistent with non-stationary behaviour rather than stationary behaviour, and that the first differnce in the level of the index (inflation) is not mean reverting enough.

Note 4. See Freedman (1994) for a discussion of the use of the MCI by the Bank of Canada.

Note 5. Under the null of p-r unit roots $\lambda_{i}, i=r+1, \ldots p$, should behave like random walks and the trace test statistic should be small. Starting with the null hypothesis of full rank, the rank is determined by the top-bottom procedure until the null cannot be rejected (Juselius, 2006).

Note 6. Juselius (2006) emphasises that in many cases the estimated eigenvectors are not economically interpretable and that "any attempt to do so does not make any sense" (p.128). 


\section{Macrothink Institute ${ }^{T M}$}

Note 7. Sims and Zha (1999) show that the use of 1- or 2-standard deviation bands can give a misleading impression because impulse responses often have a highly asymmetrical distribution. They recommend using fractiles instead of standard deviation bands.

Note 8. Although the real exchange rate was also found to be weakly exgonenous, it was include as an endogenous variable because it is presumably affected by the domestic interest rate, as well as the other domestic and external variables.

Note 9. The regime probabilities for a 3-state model are presented in the Appendix. Overall, the filter only identified an outlier third state in late-1970 and early-1980 which was not long enough to estimate that state's parameters with any confidence.

Note 10 . The RCM statistic is essentially a sample estimate of its variance.

Note 11. See Tillmann (2007) for a discussion of this version of the test.

\section{Appendix}
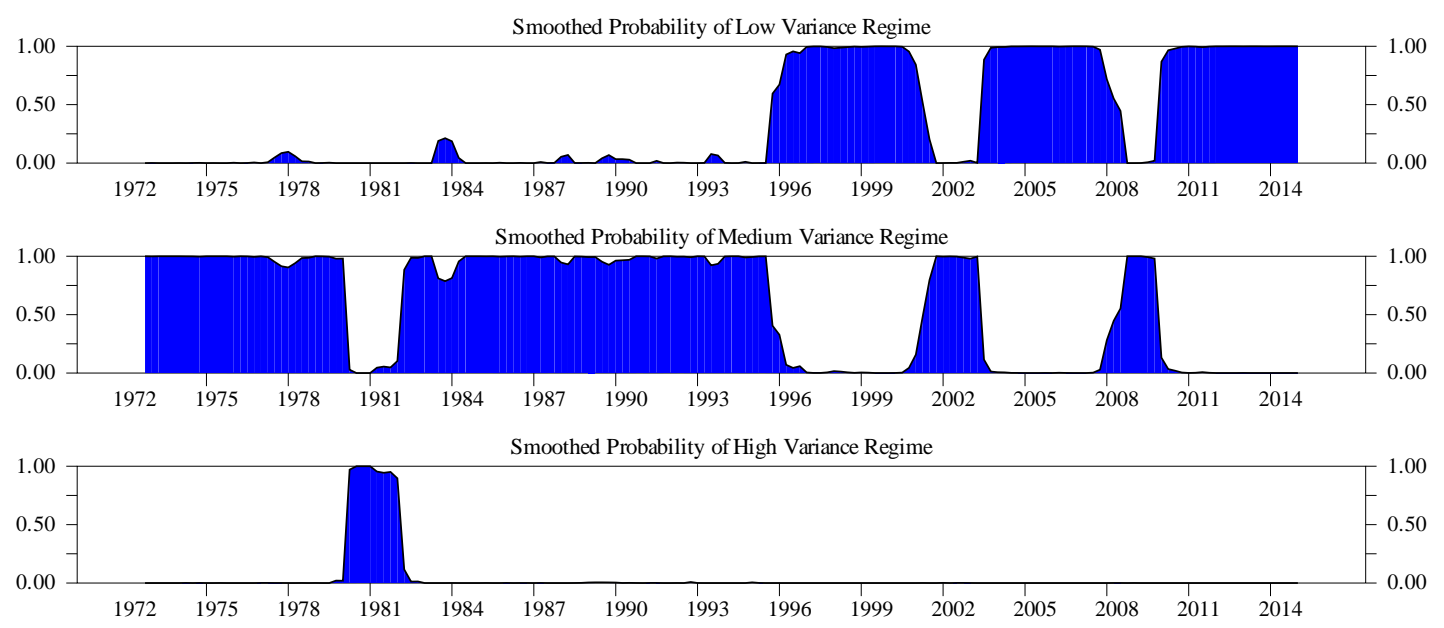

Figure 1A. Smoothed Filtered Probabilities for the 3-Regime Estimation

\section{Copyright Disclaimer}

Copyright for this article is retained by the author(s), with first publication rights granted to the journal.

This is an open-access article distributed under the terms and conditions of the Creative Commons Attribution license (http://creativecommons.org/licenses/by/3.0/). 